\title{
XIV. On the north-west magnetic pole
}

\section{Colonel Macdonald}

To cite this article: Colonel Macdonald (1821) XIV. On the north-west magnetic pole , Philosophical Magazine Series 1, 57:274, 88-93, DOI: 10.1080/14786442108652465

To link to this article: http://dx.doi.org/10.1080/14786442108652465

曲 Published online: 27 Jul 2009.

Submit your article to this journal $\pi$

Џll Article views: 3

Q View related articles $₫$ 


\section{$[88 j$}

\section{On the North-west Magneitc Pole. By Colonel MaCdonal.}

Summerland-place, Exeter, Dec. 15 .
No event will be deemed more remarlsable by future ages, than the decided discovery of the actural existence of a north-u'est magnetic pole, by the hardy and enterprising navigators of the passing century. The vast importance of the fact is of the utmost consequence, as it must, infallibly, in time, lead to certain theory of the difference of the variations of the magnetic needle. Dr. Halley had recourse to the supposition of four magneric poles belonging to a magnetic nucleus revolving within the earth, from east to west ; and thus he attempted to account for the rariation, and its changes, supposed to have been first observed hr Columbus and Sebastian Cabot. Euler, under a very plausible and ingenious theory, supposed only two magnetic poles. $\mathrm{Mr}$. Churchman adopted the idea of two magnetic poles; and imagined the northern one to move eastward, on a parallel of latitude, while the southern moved slower; the former taking 1096 rears in its revolution, while the latter required 2289 . 'The north-west pole was supposed by these philosophers to be situated not far from where the recent discovery has placed it. The deflection of the needle has been found by the navigators in the discovery ships, to have exceeded one-fourth of a great circle. Captain Cook in his voyages approached nearly, in the south hemisphere, to the supposed situations of the south magnetic poles, and found ro quantum of variation that could at all sanction the supposition of their actuality. This certainly furnishes strong evidence that these poles are more imaginary than real; and tirat all future theorics of variation must, necessarily, be deduced from the well-known attraction of the north and south poles of the earth, combined with the ascertained action of the northwest magnetic pole, whose positive discovery refiects so much credit on the present age. This is still further confirmed by a general remark to be made on the variations of Cook; viz. that in southern latitude particularly, they were, in east and west longitude, of opposite descriptions, and decidedly influenced, relatively, by the magnetic pole, whose position is now nearly known. Had the southern poles existed, the approximation to their imagined situations, by several circumnavigators, must, from the known laws of magnetism, have given rise to so strong an attraction of the south end of the magnetic needle, as would have made the variation three times, at least, greater than it has proved; independent of causing it to be of a different nature from what actually appears in the records of voyages.-Thus, then, this interesting subject seems to be reasonably clcared from

\footnotetext{
* From The Gentleman's Mafazine for December 1820.
} 
the embarrassment of southern magnetic poles, beyond the requisite one of the south end of the earth's axis: and all future reasoning (till experience and experiment carry us further) must be founded less on hypothesis, and more on fact, than has hitherto been the case.

Having premised thus much, we come to the consideration of the wonderful and inexplicable phænomenon in nature, the accounting for which has induced so many eminent scientific characters to form the theories briefly mentioned above.-Professor Gillebrand having compared his own observations of the variation with those of others, ascertained that it gradually increased westward. In the year 1576 the variation was found to be $11^{\circ} 15^{\prime}$ east, in London. It diminished gradually till 1662 (or 1657, by other accounts), when it became nothing; or in other words, the magnetic needle pointed to the true north. In $1666, \mathrm{Mr}$. Sellers made the variation $0^{\circ} 34^{\prime}$ west. Since that period the variation has been increasing westward, and during the three last years it has remained nearly stationary. In comparing its progress during similar periods, it does not appear that the rate of increase is equable, as it varies from one or two minutes, to a medium annual increase of $9^{\prime} 48^{\prime \prime}$. - In the Royal Society's Rooms, the mean variation in June 1817 was $24^{\circ} 17^{\prime} 54^{\prime \prime}$; and in June 1818 it was in mean quantity $24^{\circ} 17^{\prime}$. In June 1819 , it was found to be $24^{\circ} 15^{\prime} 43^{\prime \prime}$; from which it would seem that it had begun to return. It was found, by Captain Cook, that the same observers, with the same compass, in the same day, made a difference of five and six degrees; and nearly the double of this was found as a difference between the variation taken on the ice, and on board ship in Baffin's Bay. This leads to the clear conclusion, that observation on terra firma can alone be depended upon for real accuracy.

The dip of the needle, or its inclination to the nearest pole (and I have some reason to conclude that this also is subject to a daily small variation), was an accidental discovery, marle by Mr. Norman, in balancing his needles. It was in 1576 found to be $71^{\circ} 50^{\prime}$ at London; and in June 1819 it was about $70^{\circ} 51^{\prime}$ in the Royal Society's Rooms. In the very same situation, at different periods, both the variation and dip are different; and the dip does not correspond to change in latitude under the same meridian; nor is the same dip given by the same dipping needle, at sea, on the same day. This again indicates the necessity of observing the dip also on shore, when real accuracy is wanted. If the variation and dip were not constantly altering in the same place, a certain theory might be arrived at; but when the contrary proves to be the fact, the attempts made to lay down on the globe a curve of no magnetic variation, is useless, if not absurd. Vol.57. No.274. Fel.'1821. 
A sinall needle compared to a large real magnet, is experimentally found to furnish a similar effect to a magnetic compass-card, acted on by some invisible magnetic power within the body of the earth. This leads to the certain conclusion, that the changes in variation, and those much less in dip, arise from a corresponding change or movement in the cause. I have made the remarks contained in this paper,"because I am led to believe that the recent discovery of a north-west magnetic pole has put it in the power of experimental philosophy to establish, in time, the law of movement of the magnetic cause producing effects which have hitherto baffled all human rescarch. The anomalies of the variation observed by different persons in the same year, in London, clearly evince that the application of a needle to a meridian-line accurately laid down, can alone furnish the precise variation at the place of observation.-In two papers by me, in the Philosophical Transactions for 1796 and 1798, the process of laying off such a meridian is described; and this was done for the purpose of ascertaining accurately, not only the variation, but also the variation of the variation, or the diurnal vibrating variation, at Bencoolen or Sumatra; and afterwards, at the island of St. Helena. Professor Gillebraud first noticed this diurnal variation in 1635 . This vibrating variation moves and returns through a few minutes of a degree, daily; and in different places its direction and quantity do not correspond. Many theories have been formed, in order to account for this extraordinary magnetic phænomenon; and the experiments made by the application of heat to magnets, afford, probably, the most plausible solution of the case: but a series of accurate observations on meridians, in many distaut situations, are requisite to remove serious objections lying against the best-imagined of these conjectural theories.

From the dip of the necdle it is quite unquestionable that the magnetic power, or cause, lies at some unknown depth under the surface of the earth. Mr. Apinus, of the Imperial Academy of St. Petersburgh, las distinctly traced the close and intimate analogy between magnetism und electricity : and the Galvanic experiments lately made by the prince of chemists, Sir Humphry Davy, place the fact beyond all doubt. Experiments show that an subtle fluid of these united descriptions pervades the atmosphere, and iron, magnetised and otherwise; forming a constant and invisible communication between the magnetic cause within the earth and common magrictic needles. There is now every reason to conclude, that the aurora borealis constitutes a magnetic current between the real north pole and the north-west magnetic pole; the one giving ont to the other an excess of fluid, in order to restore an equilibrim between positive and negative quantities. This supposition may not be quite gratu- 
itous, as we generally observe the aurora borealis to act in this direction.

It is utterly impossible to attempt to account for the constant increase of the variation, without supposing that the north-west magnetic pole has a constant motion round the north pole of the earth in longitude, on a parallel of latitude; or in an elliptic curve. Though the variation, when first discovered, was only $11^{\circ} 15^{\prime}$ east, there can be little doubt but that those who are destined to exist in the year 2040 , or about that period, will find the variation as much east, as it is now west. The north pole appears to attract more powerfully than the north-west magnetic pole, as must be the case on the supposition of a revolutionary movement indispensable for the formation of any tolerable theory of the variation. The great difficulty in the way of a theory of magnetic revolution, arises from that of accounting for the fact of no variation found in some places. The solution of this difficulty may be found in a fair supposition, that the north pole, the moving magnetic pole, and the place of no variation on the surface of the earth, may be at the time nearly in one line. I found, by continued observations during two years, that the variation at Bencoolen was $1^{\circ} 7^{\prime}$ to $1^{0} 11^{\prime}$ east ; the vibrating rariation giving a returning swing of about four minutes of a degree. Capt. Cook found the variation in the Straits of Sunda to be $1^{\circ}$ west.-At Condore in $8^{\circ} 6^{\prime}$ north, and $106^{\circ} 1 S^{\prime}$ east longitude, the variation was $0^{\circ} 1 i^{\prime}$ west. Now these, and many other places of nearly un variation, are nearly in the line, vertical plane, or section of the two poles; and, consequently, the variation must, necessarily, be little or nothing. The well-known fact that the variation is constantly changing in one and the same place, furnishes no smalt proof in favour of the theory of movement of the secondary magnetic cause, or north-west magnetic pole. - The variation in London was nothing in 1662 , or 158 years ago. Supposing the new pole to be situated in 10 fo $^{\circ}$ of west longitude, it would reguire 568 years, nine months, and eighteen days, to effect its revolution under the parallel of its supposed movement. - In 243 years the dip of the needle appears to have diminished in London only 59 minutes of a degree. This would seem to indicate that the movement of the magnetic pole is more in a straight line, nearly in an east and west direction, than in a circular or elliptical curve, round the north pole of the earth. Bond makes the variation nothing in London in 1657. The olservations regularly taken by our librarian, at the rooms of the Royal Society, may be relied on. It would appear from them, that the west variation has ceased, or turned. The variation, therefore, has taken (allowing the change to have been in 1818) ahont 161 years to attain its ut- 
most westing. It being reasonable to suppose that the magnetic pole will move as far to the east as it has to the west of the meridian of London, the whole period of its movement in a straight line within the earth, from west to east, will he thus 322 years. In the year 1600 the variation at St. Helena was $8^{a}$ east. In 1692 it was $1^{\circ}$ west. In 1796 I make it there, from a medinm of morning and evening observations on a meridian, $15^{\circ} 48^{\prime} 34^{\prime \prime} \cdot 5$; while in London, in 1795 , it was $23^{\circ} 57^{\prime}$. - It is experimentally found, that magnetic action, like that of heat, diminishes inversely as the squares of the distances. Again, the south pole, after passing the equator, attracts the south end of the dipping needle (which must, necessarily, possess a north polarity), and the east and west variation in south latitude are generally less than in similar situations in the northern hemisphere. The action of the south pole, combined with the other cause stated, may go far in accounting for this anomaly.

It was essentially necessary to take the foregoing view of this most wonderful and interesting subject, previously to recommending the commencement of a most important series of experiments calculated to ascertain decidedly, whether the recently discovered north-west magnetic pole has, or has not, a periodical movement corresponding to east and west variation, increasing and decreasing, as has been observed. There can be but one infallible mode of making this grand and conclusive experiment, and $\mathrm{I}$ take your widely circulating and valuable publication as the channel through which I earnestly call the attention of philosophers and men of science, to a sublime discovery, which British daring and fearless enterprise has, at length, put within the reach of patient and accurate investigation.

The position of the north-west magnetic pole has been approximated, to a moral certainty. - I take it for granted, that the discovery-ships will proceed again to explore to the utmost the chamels in the Polar Basin, to the westward of Baffin's Bay. 'The principal object must be the ascertaining precisely the position of the new pole, or I would rather denominate it, the moving magnetic power, of whose existence no further doubt can remain.-This having been happily achieved by the bold commander, and by his companions, who have deserved so much of their country, a meridian should be accurately laid off, at some distance from the site of the new magnetic power. The graduated circumference and needle applied to this meridian, ought, in principle and construction, to resembie those used by me, and described in the papers I have alluded to. The meridian sustained by a strong post, might be sheltered by a small building devoid of iron. Careful observations made, annually, for a few years, on this meridian, would clearly determine whether or not the 
north-west magnetic pole had a movement, and the direction and annual quantity of such movement, if thus found to take place. Huts, but no natives, have been seen in these hyperborean regions. If, however, natives should appear next year, the meridian, to remain undisturbed, might be concealed in an excavation, or situated in some secret place.

The observation of the variation of the variation, on this meridian, would be an important object of unremitting attention. In my papers I ascribed it to the action of the sun's heat, increased and diminished during the earth's revolution on its axis. I venture to conjecture, that this species of variation will (on the principle of heat acting on the northern poles, alternately) be found to move in an opposite direction to that observed in London. Should this prove to be the fact, the cause of the diurnal variation will be thus completely set at rest. The utmost efforts will be made to ascertain the precise position of the new pole; and if it should be impracticable to make the essential observations suggested, in its vicinity, the purpose will be equally answered by taking them to the east of Copper Mine River, at the point where west variation ceases, and east commences. The Regent's Channel may, probably, lead to this situation; if not, it can be attained to over-land, from the north-west of Hudson's Bay.

If the discovery I suggest in these imperfect statements is made in due time, it will be the greatest and most important in scientific history: and it is by giving circulation and publicity to papers of this description, that such valuable results can be arrived at.

XV. On the Application of the explosive Power of Coal Gas as a First Mover in Machinery. By Gronge Lowe, Esq.

\section{To Mr. Tilloch.}

Sin, - IN this truly fertile age of invention, when the fiell of philosophic inquiry teems almost to its very highways and hedges with sportsmen, some actuated by fame, honour and pleasure; others by the stimulus of profit, in discovering "some new thing under the sun:"--To you, Mr. Editor, who see so much of these sportsmen, and who receive so much of their game, it cannot appear strange that you should so often be called upon to decide the squabbles of anticipated shots, and to say to whom the feather belongs. This is partly the reason for my now stepping out of the jog-trot path of life to present myself before you. What a truly motley group, in your eye, must this field of philosophic sportsmen present! The pen of Juvenal or the needle of 